\title{
Application of rapid in vitro co-culture system of macrophages and T-cell subsets to assess the immunogenicity of dogs vaccinated with live attenuated Leishmania donovani centrin deleted parasites (LdCen $-/-)$
}

Kelvinson Fernandes Viana ${ }^{1,2}$, Jacqueline Araújo Fiuza ${ }^{3}$, Sreenivas Gannavaram ${ }^{4}$, Ranadhir Dey ${ }^{4}$, Angamuthu Selvapandiyan ${ }^{5}$, Daniella Castanheira Bartholomeu ${ }^{6}$, Denise da Silveira-Lemos ${ }^{7}$, Lilian Lacerda Bueno ${ }^{6}$, Walderez Ornelas Dutra ${ }^{1}$, Ricardo Toshio Fujiwara ${ }^{6}$, Hira L. Nakhasi ${ }^{4}$ and Rodolfo Cordeiro Giunchetti ${ }^{1 *}$

\begin{abstract}
Background: Live attenuated Leishmania donovani parasites as LdCen ${ }^{-1-}$ were shown to confer protective immunity against Leishmania infection in mice, hamsters, and dogs. Strong immunogenicity in dogs vaccinated with $\mathrm{LdCen}^{-/-}$has been previously reported, including increased antibody response favoring Th1 response lymphoproliferative responses, $\mathrm{CD} 4^{+}$and $\mathrm{CD} 8^{+}$T-cells activation, increased levels of Th1 and reduction of Th2 cytokines, in addition to a significant reduction in parasite burden after 18 and 24 months post virulent parasite challenge.
\end{abstract}

Methods: Aimed at validating a new method using in vitro co-culture systems with macrophages and purified CD4 ${ }^{+}$ or $\mathrm{CD}^{+}$or $\mathrm{CD}^{+}: \mathrm{CD}^{+} \mathrm{T}$-cells of immunized dogs with both $\mathrm{LdCen}^{-/-}$and Leishmune ${ }^{\circledast}$ to assess microbicide capacity of macrophages and the immune response profile as the production of IFN- $\gamma$, TNF- $a$, IL-12, IL-4 and IL-10 cytokines.

Results and discussion: Our data showed co-cultures of macrophages and purified T-cells from dogs immunized with $\mathrm{LdCen}^{-/-}$and challenged with $\mathrm{L}$. infantum were able to identify high microbicidal activity, especially in the co-culture using CD4 ${ }^{+}$T-cells, as compared to the Leishmune ${ }^{\circledast}$ group. Similarly, co-cultures with $C D 8^{+}$T-cells or $C D 4^{+}: C D 8^{+}$T-cells in both experimental groups were able to detect a reduction in the parasite burden in $L$. infantum infected macrophages. Moreover, co-cultures using $\mathrm{CD}^{+}$or $\mathrm{CD}^{+}$or $\mathrm{CD}^{+}: \mathrm{CD}^{+}{ }^{+}$-cells from immunized dogs with both $\mathrm{LdCen}^{-1-}$ and Leishmune ${ }^{\oplus}$ were able to identify higher levels of IFN- $\gamma$ and IL-12 cytokines, reduced levels of IL-4 and IL-10, and a higher IFN- $/ / \mathrm{LL}-10$ ratio. While the highest IFN- $\gamma$ levels and IFN- $/ / \mathrm{LL}-10$ ratio were the hallmarks of $\mathrm{LdCen}^{-/}$group in the coculture using $\mathrm{CD}^{+}{ }^{+}$-cells, resulting in strong reduction of parasitism, the Leishmune ${ }^{\circledast}$ immunization presented a differential production of TNF-a in the co-culture using $\mathrm{CD} 4^{+}: \mathrm{CD} 8^{+} \mathrm{T}$-cells.

(Continued on next page)

\footnotetext{
* Correspondence: giunchetti@gmail.com; giunchetti@icb.ufmg.br ${ }^{1}$ Laboratory of Cell-Cell Interactions, Morphology Department, Institute of Biological Science, Federal University of Minas Gerais, Av. Antônio Carlos, 6627, Pampulha, Belo Horizonte, Minas Gerais 31270-901, Brazil

Full list of author information is available at the end of the article
} 
(Continued from previous page)

Conclusion: The distinct conditions of co-culture systems were validated and able to detect the induction of immune protection. The method described in this study applied a new, more accurate approach and was able to yield laboratory parameters useful to test and monitor the immunogenicity and efficacy of Leishmania vaccines in dogs.

Keywords: Vaccine, In vitro co-culture, CD4 ${ }^{+}$and CD8 ${ }^{+}$T-cells, Canine visceral leishmaniasis LdCen $^{-/}$, Leishmune $^{\oplus}$

\section{Background}

Leishmaniasis is a protozoonosis that is endemic in several countries around the world, with more than 350 million cases being visceral leishmaniasis [1]. The impact of controlling the infected dog population to reduce human visceral leishmaniasis prevalence in these endemic areas has been debated [2-4]. Therefore, the development of a canine visceral leishmaniasis (CVL) vaccine is highly desirable and would represent the most practical and efficient control tool [5].

A key goal in the control of CVL has been the development of vaccines with high protective capability to interrupt the parasite transmission [6]. Assessments of vaccine safety and anti-CVL efficacy generally require a long follow-up, extending into years of study [7-9]. Thus, researchers need to develop methodological strategies that enable a more rapid and accurate evaluation of the dog's immune system. Such tests could be included in clinical trials of vaccines against CVL, so that the time needed for the experiments could be reduced. This would likely reduce the costs of experimentation using the dog model and provide a more rational way of selecting candidate vaccines against CVL.

Among the live-attenuated parasites used as vaccines, the centrin deletion in $L$. donovani $\left(\mathrm{LdCen}^{-/}\right)$has been shown to specifically affect the cytokinesis and lead to multinucleated cells and eventual cell death of amastigote forms while the growth of promastigote forms is unaffected. Previous studies evaluated the protective immunity of $\mathrm{LdCen}^{-/}$and demonstrated the safety, immunogenicity, and protection against infection with wild type $L$. donovani in mice and hamster models [10]. Recently, we have demonstrated that immunization with $\mathrm{LdCen}^{-/-}$results in an increase in immunoglobulin isotypes, higher lymphoproliferative response, higher frequencies of activated $\mathrm{CD}^{+}$and $\mathrm{CD}^{+}$ T-cells, IFN- $\gamma$ production by $\mathrm{CD}^{+} \mathrm{T}$-cells, increased secretion of TNF- $\alpha$ and IL-12, and decreased secretion of IL-4, as well as a significant reduction in parasite burden 18 and 24 months after experimental challenge in dogs [11].

Recently, an in vitro co-culture system using macrophages and purified T-cells was standardized to analyze the adaptive immune response in dogs immunized against CVL [12]. In this study, we applied the same method using $\mathrm{LdCen}^{-/-}$and Leishmune ${ }^{\oplus}$ vaccines, which have been reported to induce a strong immune response against canine visceral leishmaniasis. The microbicidal capability of macrophages co-cultured with $\mathrm{CD}^{+}$or $\mathrm{CD}^{+} \mathrm{T}$-cells or $\mathrm{CD}^{+}: \mathrm{CD}^{+} \mathrm{T}$-cells simultaneously was assessed after in vitro infection with $L$. infantum and the cytokine levels were analyzed from dogs after 24 months of the experimental challenge with L. infantum. The results suggest that this in vitro co-culture system allows rapid efficacy analysis of vaccines against canine visceral leishmaniasis.

\section{Methods \\ Parasites}

The wild type strain of L. infantum (MHOM/BR/1970/ $\mathrm{BH} 46)$ was used for the in vitro co-culture system. The parasites were grown in NNN/LIT (Sigma Chemical Co., USA) culture medium supplemented with inactivated $20 \%$ fetal bovine serum (FBS) (Cultilab, Brazil), plus penicillin $(200 \mathrm{U} / \mathrm{ml})$ and streptomycin $(100 \mu \mathrm{g} / \mathrm{ml})$, at $\mathrm{pH} 7.4$ and incubation temperature of $23{ }^{\circ} \mathrm{C}$. Parasites used for in vitro tests were removed from the culture at the stationary phase (seventh day of culture) during the seventh passage. Parasites were counted in a Neubauer chamber, from which more than $90 \%$ viability was obtained and later used for in vitro infection.

\section{Animals and vaccination protocol}

Eighteen healthy beagle dogs with 8 months of age were divided into three groups (three males and three females per group). The L. donovani centrin-deleted $\left(\mathrm{LdCen}^{-/-}\right)$ parasites were used for immunization. The $\mathrm{LdCen}^{-/}$ group received $10^{7} \mathrm{LdCen}^{-/-}$stationary phase promastigotes subcutaneously (single-dose). The Leishmune ${ }^{\bullet}$ group received three subcutaneous doses of vaccine ( $1 \mathrm{ml}$ each) with an interval of 21 days between each dose, as recommended by the manufacturer (Zoetis, Brazil). The Control group received PBS alone. All animals were challenged 2 months after the last dose of vaccine (Leishmune ${ }^{\ominus}$ or $\mathrm{LdCen}^{-/-}$) or PBS. The blood collection to analyze the co-culture systems was performed 24 months after an intravenous challenge with $10^{7}$ of stationary phase promastigotes of L. infantum.

\section{Ethical approval}

The study was approved by the Ethical Committee for Use of Experimental Animals of the Federal University of Minas Gerais, Brazil (CETEA Protocol no.122/09 and 288/2012). 


\section{Isolation of peripheral blood mononuclear cells}

Blood samples $(10 \mathrm{ml}$ each) from the 17 dogs (control group: $n=6$; Leishmune ${ }^{\odot}$ group: $n=5$; LdCen $^{-/-}$group: $n=6)$ were collected in heparinized tubes intended for obtaining peripheral blood mononuclear cells (PBMC), as previously described [13]. Briefly, the whole blood volume collected was placed in a mixture of FicollHypaque (Sigma Chemical Co.; density: $1.119 \mathrm{~g} / \mathrm{ml}$ ) and Ficoll-Hypaque (Sigma Chemical Co.; density: $1.077 \mathrm{~g} /$ $\mathrm{ml}$ ) at a 1:3 ratio (Ficoll/blood) in sterile polystyrene conical bottom tubes (Falcon, Corning, USA). All samples were centrifuged at $700 \times g$ for $80 \mathrm{~min}$ at $22{ }^{\circ} \mathrm{C}$. The PBMC ring was collected at the Ficoll-Hypaque interface and transferred to another tube with $40 \mathrm{ml}$ of Falcon sterile $1 \times$ PBS containing $10 \%$ FBS. This tube was centrifuged twice at $400 \times g$ for $10 \mathrm{~min}$ at $4{ }^{\circ} \mathrm{C}$. After the supernatant was discarded, the cells were resuspended in $1 \mathrm{ml}$ of cell culture medium RPMI 1640. Cells were counted in a Neubauer hemocytometer chamber to determine the numbers of monocytes or lymphocytes per milliliter.

\section{Microbicidal activity}

The microbicidal activity was assessed using monocytes, which were adjusted and plated at $5 \times 10^{5}$ monocytes/well using 24-well plates (NUNC, Thermo Fisher Scientific Inc., USA), on circular coverslips (15 mm; Glasscyto, Brazil), as previously described [13]. Briefly, cultures were established using RPMI supplemented with $20 \%$ fetal calf serum on $20 \%$ macrophage colony-stimulating factor medium obtained from supernatant of cultures of L929 immortalized cells, and incubated at $37{ }^{\circ} \mathrm{C} / 5 \% \mathrm{CO}_{2}$. Monocytes differentiating into macrophages were evaluated at 5 days of culture, as previously described [12, 13]. The cells were infected with $5 \times 10^{6}$ of $L$. infantum promastigotes in the stationary phase, using a 10:1 ratio (ten parasites per macrophage). Each well was gently washed $3 \mathrm{~h}$ after infection, and the cultures were maintained in co-culture with $\mathrm{CD}^{+}$or $\mathrm{CD}^{+} \mathrm{T}$-cells or $\mathrm{CD}^{+}: \mathrm{CD}^{+} \mathrm{T}$-cells simultaneously to assess microbicidal activity at $72 \mathrm{~h}$ after infection. To calculate the rate of parasitic infection, the numbers of amastigotes in 200 macrophages were counted. Afterwards, the total number of amastigotes was divided by the total number of infected macrophages to obtain the average number of amastigotes per macrophage $[12,13]$.

\section{Purification of $\mathrm{CD}^{+}$and $\mathrm{CD} 8^{+}$T-cells}

After obtaining the PBMC by Ficoll-Hypaque gradient, lymphocytes were submitted to further purification, as previously described $[12,13] . \mathrm{CD}^{+}$and $\mathrm{CD}^{+} \mathrm{T}$ lymphocytes were isolated using magnetic beads (Miltenyi Biotec Inc., USA) by positive selection using anti-CD4 or anti-CD8-FITC (fluorescein isothiocyanate) antibodies (AbD Serotec, UK) and microbeads coated with anti-
FITC. Cell suspension was prepared at a concentration of $6 \times 10^{7}$ cells in a $1-\mathrm{ml}$ tube in an isolation buffer containing PBS $1 \times$, pH 7.2, $0.5 \%$ BSA, and 2 mM EDTA. Monoclonal antibodies (CD4 or CD8-FITC) were added to $2 \mu \mathrm{l} /$ $\mathrm{ml}$ of total lymphocytes and incubated at room temperature (RT) for $15 \mathrm{~min}$. Next, magnetic microbeads were added to $10 \mu \mathrm{l} / \mathrm{ml}$ lymphocytes and incubated for $15 \mathrm{~min}$ at RT. Cell suspension was loaded into a MACS column (Miltenyi Biotec Inc.), which was placed in the magnetic field of a MACS separator. The magnetically labeled $\mathrm{CD}_{4}^{+}$or $\mathrm{CD}^{+}$cells were retained in the column, whereas the unlabeled cells ran through, resulting in this cell fraction being depleted of $\mathrm{CD}^{+}$and $\mathrm{CD}^{+}$cells. After removing the column from the magnetic field, the magnetically retained $\mathrm{CD}^{+}$and $\mathrm{CD}^{+}$cells were eluted as the positively selected cell fraction by washing the magnetic column with $15 \mathrm{ml}$ of isolation buffer.

The purity of $\mathrm{CD}^{+}$and $\mathrm{CD}^{+}$T-cells was evaluated by flow cytometry on a FACSCalibur instrument (Becton Dickinson, USA) interfaced to an Apple G3 workstation. Cell-Quest software (Becton Dickinson) was used for both data acquisition and analysis. A total of 20,000 events were acquired for each preparation. Flow cytometric analysis was performed using canine whole blood leukocytes that were selected on the basis of their characteristic forward (FSC) and side (SSC) light-scatter distributions. Following FSC and SSC gain adjustments, the lymphocytes were selected by gating 1 on the FSC versus SSC graph. Fluorescence was evaluated from FITC spectra (anti-CD4 and anti-CD8 antibodies) on FL1 in dot plot representations. A marker was set as an internal control for nonspecific binding to encompass $>98 \%$ of the unlabeled cells, and this marker was then used to analyze data for individual animals. The results were expressed as the percentage of positive cells within the selected gate for T-cell surface markers presenting $\mathrm{CD}^{+}$or $\mathrm{CD}^{+}$.

\section{Co-culture system}

After purification, the $\mathrm{CD}^{+}$and/or $\mathrm{CD}^{+}$T-cells were incubated with macrophage (Mac) previously infected with L. infantum promastigotes (10 parasites per macrophage) in the following proportions: to $\mathrm{CD}^{+} \mathrm{T}$-cells: Mac - 1 lymphocyte for each 2 macrophages (1:2) and to CD8 ${ }^{+}$T-cells: ac - 1 lymphocyte for each 2 macrophages (1:2). The culture of $\mathrm{CD}^{+}$: $\mathrm{CD}^{+} \mathrm{T}$-cells simultaneously incubated under the same condition used ratios of 1:1:1 $\left(\mathrm{CD}^{+}: \mathrm{CD}^{+}: \mathrm{Mac}\right)$. Cells were grown in this co-culture system for $72 \mathrm{~h}$, as previously described [12, 13]. Afterwards, the well supernatants were collected and stored at $-80{ }^{\circ} \mathrm{C}$ for later cytokine measurements.

\section{ELISA cytokine assay}

Culture supernatants were collected at $72 \mathrm{~h}$, and the levels of IFN- $\gamma$, TNF- $\alpha$, IL-12, IL-4, and IL-10 were 
titrated in culture supernatants using the ELISA method (R\&D Systems, USA). The plates were coated with antiIFN- $\gamma$, anti-TNF- $\alpha$, anti-IL-12, anti-IL-4, and anti-IL-10 $\mathrm{mAb}$ in $\mathrm{PBS}, \mathrm{pH} 7.4$, and incubated at $4{ }^{\circ} \mathrm{C}$ overnight. After blocking the wells using buffer containing PBS plus $0.05 \%(v / v)$ Tween 20 and $0.1 \%(w / v)$ BSA, supernatants were added to each well. Biotin-labeled mAb in an incubation buffer was added to each well, and streptavidin-HRP was used as an enzyme. The reaction was developed using 3,3',5,5' -tetramethylbenzidine substrate and stopped by adding a $2.5 \mathrm{M} \mathrm{H}_{2} \mathrm{SO}_{4}$ solution. The plates were washed after each step using PBS plus $0.05 \%(v / v)$ Tween 20. Minimum sensitivity levels were $119 \mathrm{pg} / \mathrm{ml}$ for IFN- $\gamma, 109 \mathrm{pg} / \mathrm{ml}$ for TNF- $\alpha, 102 \mathrm{pg} / \mathrm{ml}$ for IL-12, 118,08 pg/ml for IL-4, and $89 \mathrm{pg} / \mathrm{ml}$ for IL-10. All experiments were performed using 96-well plates (COSTAR, Corning Inc., USA) and according to R\&D Systems instructions. Reading was performed using a microplate automatic reader (EL800; Biotek, Winooski, VT, USA) at a wavelength of $450 \mathrm{~nm}$.

\section{Statistical analysis}

Statistical analysis was performed with GraphPad Prism 5.0 software (Prism Software, CA, USA). Data normality was assessed using the Kolmogorov-Smirnov test. The analyses of co-cultures and cytokines were performed using repeated ANOVA measurements. Differences were considered significant at $P<0.05$.

\section{Results}

Immunization with $\mathrm{LdCen}^{-/-}$attenuated parasites resulted in significant microbicidal activity of macrophages co-cultured with $\mathrm{CD}^{+}{ }^{+} \mathrm{T}$-cells associated with increased levels of Th1 cytokines

The performance of the co-culture system was evaluated, including $\mathrm{CD} 4^{+} \mathrm{T}$-cells, to analyze the contribution of this cell subpopulation in the immunogenicity establishment. After $3 \mathrm{~h}$ of in vitro infection of macrophages with $L$. infantum, macrophages from the $\mathrm{LdCen}^{-/-}$ group showed a lower $(P=0.049)$ frequency of infection (Fig. 1a) as compared to the control group. The parasite burden was reduced in macrophages in both $\mathrm{LdCen}^{-/-}$ $(P=0.0009)$ and Leishmune ${ }^{\varpi}(P=0.005)$ groups as compared to the control (Fig. 1b). Interestingly, $72 \mathrm{~h}$ after in vitro infection, $\mathrm{LdCen}^{-/-}$group displayed an intense reduction $(P=0.012)$ in parasite burden as compared to the Leishmune ${ }^{\odot}$ group (Fig. 1c). $\mathrm{LdCen}^{-/-}(P=0.008)$ and Leishmune ${ }^{\odot}(P=0.005)$ immunizations induced high levels of cytokines IFN- $\gamma$ (Fig. 1d), TNF- $\alpha$ (Fig. 1e) and IL-12 (Fig. 1f) and low levels of IL-4 (Fig. 1g) and IL-10 (Fig. 1h) in co-cultures as compared to the control group. Remarkably, the $\mathrm{LdCen}^{-/-}$presented high levels of IFN- $\gamma$ when compared to the Leishmune ${ }^{\curvearrowleft}$ group (Fig. 1d). Furthermore, both analyzed vaccines presented a high IFN- $\gamma / \mathrm{IL}-10$ ratio as compared to the control group, with $\mathrm{LdCen}^{-/-}$displaying the highest $(P=0.006)$ cytokine ratio (Fig. 1i).

\section{LdCen $^{-/-}$and Leishmune ${ }^{\circledR}$ immunized dogs induced an intense microbicidal activity of macrophages co-cultured with $\mathrm{CD}^{+} \mathrm{T}$-cells and increased levels of pro- inflammatory cytokines}

Since the $\mathrm{CD}^{+}$T-lymphocytes act as effector cells to control intracellular pathogens, this T-cell subset was included in the co-culture system to analyze the induction of memory. $\mathrm{LdCen}^{-/-}(P=0.010)$ and Leishmune ${ }^{\odot}$ $(P=0.009)$ groups presented significant reduction in the number of amastigotes in macrophages co-cultured with $\mathrm{CD}^{+} \mathrm{T}$ cells as compared to the control group (Fig. 2c). All analyzed pro-inflammatory cytokines (IFN- $\gamma$, TNF- $\alpha$, and IL-12; Fig. 2d-f) presented high levels in co-cultures of both $\mathrm{LdCen}^{-1-}$ and Leishmune groups as compared to the control group. In contrast, LdCen $^{-/-} \quad(P=0.018)$ and Leishmune $\quad(P=0.034)$ groups displayed lower levels of IL-4 (Fig. 2g) and IL10 (Fig. 2h) as compared to the control group. Interestingly, LdCen ${ }^{-/-}(P=0.006)$ and Leishmune ${ }^{\ominus}(P=0.012)$ groups showed increased IFN- $\gamma / \mathrm{IL}-10$ ratio, in addition to $\mathrm{LdCen}^{-/-}$immunization eliciting the highest $(P=$ 0.008 ) cytokine ratio (Fig. $2 \mathrm{i}$ ).

The co-culture system using macrophages plus $\mathrm{CD} 4^{+}: \mathrm{CD} 8$ ${ }^{+}$T-cells simultaneously revealed high anti-leishmanicidal activity, increased levels of pro-inflammatory cytokines, and a reduction of IL-4 and IL-10 in both LdCen ${ }^{-/-}$and Leishmune ${ }^{\circledR}$ groups

The co-culture system using macrophages associated with $\mathrm{CD}^{+}$: $\mathrm{CD}^{+}$T-cells simultaneously was employed to analyze the addictive effect of adaptive immune response in the context of T-cells subsets. In this sense, LdCen $^{-1-}(P=0.001)$ and Leishmune ${ }^{\odot}(P=0.007)$ immunizations induced a reduction in the parasite burden at $72 \mathrm{~h}$ post infection with $L$. infantum as compared with the control group (Fig. 3c). The cytokine analysis revealed high levels of IFN- $\gamma$ (Fig. 3d), TNF- $\alpha$ (Fig. 3e) and IL-12 (Fig. 3f) in both LdCen ${ }^{-/-}$and Leishmune groups $^{\oplus}$ when compared to control group. Moreover, the Leishmune $^{\oplus}$ immunization was able to induce high amounts of TNF- $\alpha$ as compared to the $\mathrm{LdCen}^{-/-}$group $(P=$ 0.042). Furthermore, both analyzed vaccines showed low levels of IL-4 (Fig. 3d) and IL-10 (Fig. 3h). Similar to cocultures using purified $\mathrm{CD}^{+}$or $\mathrm{CD}^{+}$T-cells, the coculture system using $\mathrm{CD}^{+}: \mathrm{CD}^{+} \mathrm{T}$-cells simultaneously was able to identify in $\mathrm{LdCen}^{-/-}$and Leishmune ${ }^{ø}$ groups a high $(P=0.016)$ IFN- $\gamma / \mathrm{IL}-10$ ratio, plus the $\mathrm{LdCen}^{-/-}$ group displayed the highest cytokine ratio (Fig. 2i). 


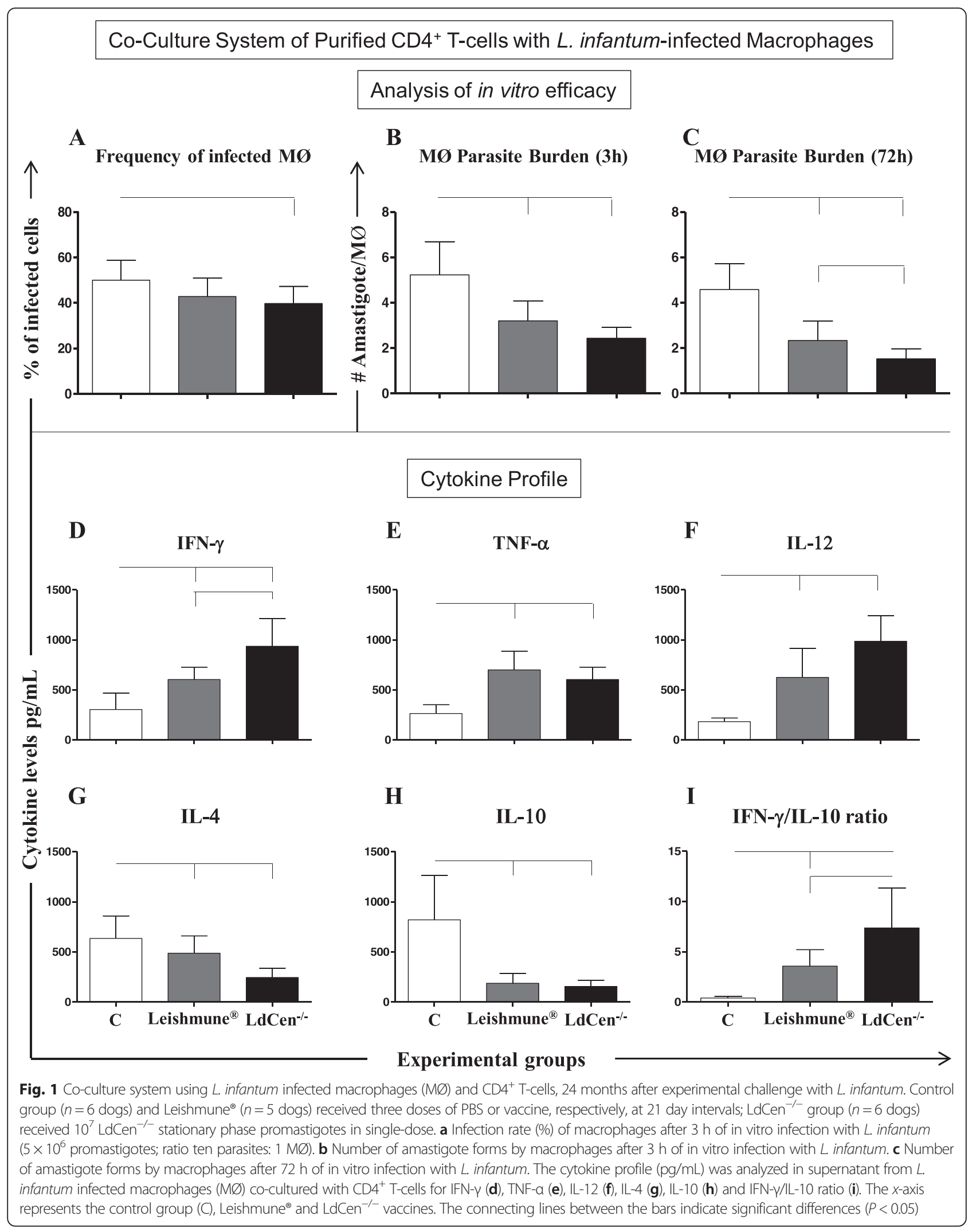




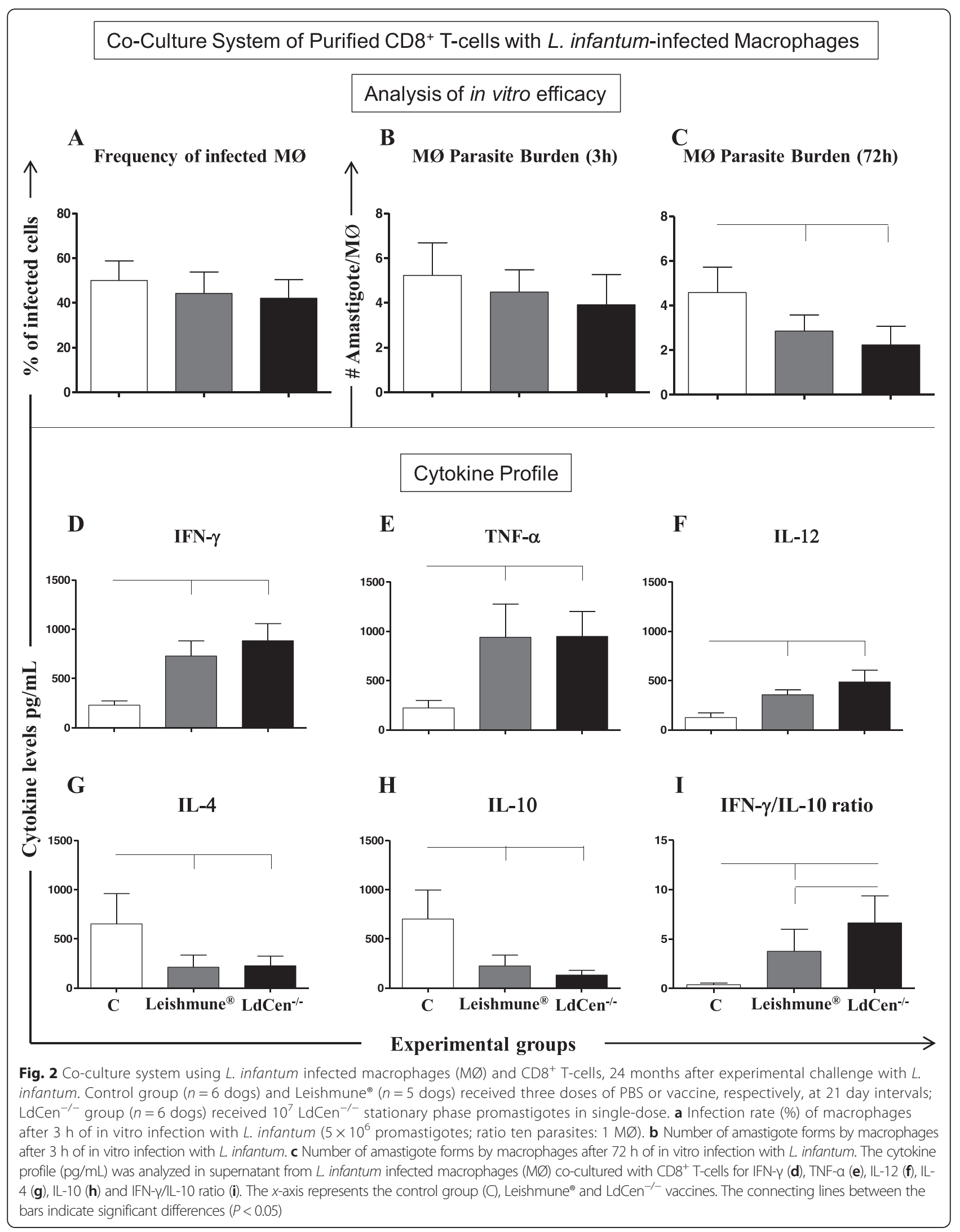




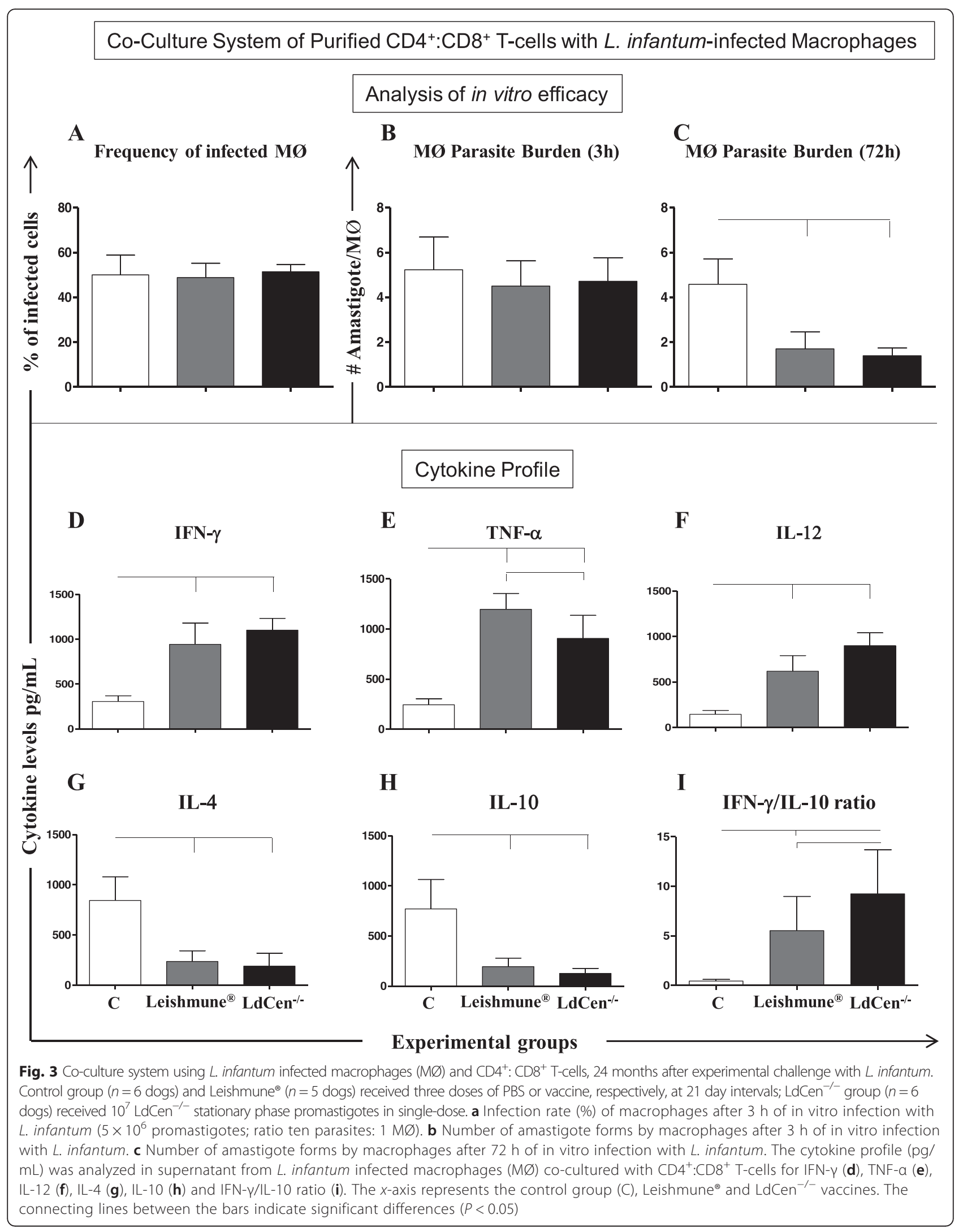




\section{Discussion}

This study applied previously standardized protocols $[12,13]$ of co-culture systems using L. infantum-infected macrophages and purified $\mathrm{CD}^{+}$or $\mathrm{CD}^{+} \mathrm{T}$ cell subsets from immunized dogs, 24 months after experimental challenge with a virulent strain of $L$. infantum. This method was previously developed to analyze vaccine candidates against canine visceral leishmaniasis $[12,13] . \mathrm{LdCen}^{-/-}$and Leishmune ${ }^{\odot}$ vaccines were used as they have demonstrated a strong immunogenicity $[10,11,14-18]$.

In this sense, it has been described that immunization with $\mathrm{LdCen}^{-/-}$in dogs elicited high levels of serum immunoglobulins, a lymphoproliferative response, and T-cell activation, which increased production of Th1 cytokines and decreased secretion of Th2 cytokines [14]. Furthermore, it was also shown that $\mathrm{LdCen}^{-/}$and Leishmune ${ }^{\circ}$ immunizations resulted in significant protection, as revealed by the low parasite burden in the bone marrow at 18 months and even 24 months post challenge [11, 14]. The parasite burden level observed in the $\mathrm{LdCen}^{-/}$and Leishmune $^{\oplus}$ immunized group is comparable to that typically observed in asymptomatic dogs, which are PCR positive [19], suggesting a robust degree of protection. These data support the application of $\mathrm{LdCen}^{-/-}$and Leishmune immunizations in the current evaluation as reference vaccines to validate the proposed co-culture system.

Most studies involving co-culture of macrophages and lymphocytes are empirically developed, using total lymphocytes, and do not reflect the cytokine levels of the Tcells. The method described in this study applied a new, more accurate approach that yields useful laboratory parameters to evaluate the ability of canine immune cells to control in vitro L. infantum infection as a biomarker to identify the immunogenicity mechanism.

Traditional immunogenicity studies in vaccines against CVL, such as Leishvacin or Leishmune ${ }^{\oplus}$, have described the biomarkers regarding increased percentage of $\mathrm{T}$ lymphocytes producing IFN- $\gamma$, especially $\mathrm{CD}^{+}{ }^{+} \mathrm{T}$-cells $[15,16]$. Moreover, LiESAp-MDP vaccine elicited protection that was correlated with the early establishment of a longlasting, predominantly Th1-type cellular immune response relationship to enhanced in vitro leishmanicidal activity of macrophages in response to higher IFN- $\gamma$ production by Tcells [20]. Recently, a study evaluating the LiESP/QA-21 $\left(\right.$ CaniLeish $\left.^{\odot}\right)$ vaccine demonstrated strong cell-mediated immune responses against the parasite despite a virulent challenge associated with a lower probability of developing active infections [21]. Furthermore, tests for microbicidal activity of macrophages cultured with autologous total lymphocytes showed that the vaccinated group inhibited twice the parasite replication in comparison with the control group [21]. However, the ideal method for identifying the protective mechanisms induced by vaccine against canine visceral leishmaniasis would analyze the effector immune response. In this sense, the leishmanicidal effect could be evaluated as an effector mechanism induced by T-cells subsets co-cultured with $L$. infantum infected macrophages.

Our data demonstrated that the three co-culture systems (L. infantum infected macrophages with purified $\mathrm{CD}^{+}$or $\mathrm{CD}^{+}$T-cells or $\mathrm{CD}^{+}: \mathrm{CD}^{+}$T-cells simultaneously) from $\mathrm{LdCen}^{-/-}$and Leishmune ${ }^{\bullet}$ were able to identify a significant reduction in the parasitic burden. Noteworthy is the fact that the co-culture system containing a purified $\mathrm{CD} 4^{+} \mathrm{T}$-cell subset was able to recognize a differential capacity of $\mathrm{LdCen}^{-1-}$ vaccine to induce a strong in vitro leishmanicidal control when compared to Leishmune ${ }^{\oplus}$ immunization. In fact, the strong leishmanicidal ability could be associated with differential IFN- $\gamma$ production in addition to a higher IFN- $\gamma / \mathrm{IL}-10$ ratio, as presented by the coculture system containing the purified $\mathrm{CD}^{+}{ }^{+} \mathrm{T}$-cell subset. In previous studies regarding asymptomatic $L$. infantum-infected dogs, co-cultures with $\mathrm{CD}^{+} \mathrm{T}$-cells and infected-macrophages were able to produce high levels of IFN- $\gamma$, whereas cells from symptomatic dogs did not [22].

Type 1 cytokine analysis has been considered a prerequisite for immunogenicity analyses before and after experimental challenge with $L$. infantum in clinical antiCVL vaccine trials $[6,12]$. In fact, the co-culture system proposed herein was able to identify the type 1 cytokine pattern, in agreement with an earlier studies for both $\mathrm{LdCen}^{-/-}$and Leishmune ${ }^{\circledast}$ immunizations $[11,14]$. Moreover, Leishmune ${ }^{\circledR}$ immunization elicited high TNF- $\alpha$ production in a co-cultured system with $\mathrm{CD} 4^{+}: \mathrm{CD}^{+} \mathrm{T}$-cells simultaneously, but without effect in producing differential parasitism control when compared to $\mathrm{LdCen}^{-/-}$. Interestingly, IFN- $\gamma$, but not TNF- $\alpha$ levels, was associated with immunogenicity and protection in dogs immunized with LBSap vaccine [23]. Furthermore, it was reported that dogs immunized with purified excreted-secreted antigens of Leishmania infantum presented high levels of IFN- $\gamma$ in coculture with $L$. infantum infected macrophages and total lymphocytes, inducing a microbicidal effect [24, 25].

Considering the previous studies describing strong immunogenicity elicited by $\mathrm{LdCen}^{-1-}$ and Leishmune immunizations, this study applied a new approach based on a co-culture system using L. infantum infected macrophages and purified T-cell subsets after vaccination and experimental $L$. infantum challenge. Data from this study indicated that the co-culture system was able to identify the immunogenicity mechanism induced by $\mathrm{LdCen}^{-/-}$and Leishmune ${ }^{\oplus}$ vaccination in dogs, in addition to associating an effector mechanism (in vitro leishmanicidal control by $L$. infantum infected macrophages) regarding an induction of T-cell memory. 


\section{Conclusions}

The low levels of type 2 cytokines (IL-4 and IL-4), high amounts of type 1 cytokines (IFN- $\gamma$, TNF- $\alpha$ and IL-12), and increased IFN- $\gamma / \mathrm{IL}-10$ ratio were associated with a leishmanicidal effect of $L$. infantum infected macrophages, using co-culture systems with $\mathrm{CD}^{+}$or $\mathrm{CD}^{+}$or $\mathrm{CD}^{+}$: $\mathrm{CD}^{+}$T-cells simultaneously. This strategy was able to validate the distinct conditions of the analyzed co-culture systems. Thus, taken together, the data point to the in vitro co-culture systems providing a rapid assay to test and monitor the immunogenicity and efficacy of Leishmania vaccines in dogs.

\section{Competing interests}

The authors declare that they have no competing interests.

\section{Authors' contributions}

Conceived and designed the experiments: KFV, JAF, DSL, RTF, and RCG. Performed the experiments: KFV, DSL, and LLB. Analyzed the data: KFV, DSL, LLB, RTF, and RCG. Contributed reagents/materials/analysis tools: SG, RD, AS DCB, WOD, RTF, HLN, and RCG. Wrote the paper: KFV, SG, RD, AS, DCB, DSL $L L B, W O D, R T F, H L N$, and RCG. All authors read and approved the final version of the manuscript.

\section{Acknowledgments}

This work was supported by Fundação de Amparo a Pesquisa do Estado de Minas Gerais, Brazil (grants CBB-APQ-02076-10/02473-10/01225-11/01052-11/ 01698-12/02007-12/02372-13, APQ-03576-13, CBB-PPM-00296-11/00609-15), Conselho Nacional de Desenvolvimento Científico e Tecnológico, CNPq, Brazil (grants 482249/2012-9, and 480979/2013-8), and CAPES. WOD, RTF, and RCG are grateful to CNPq for fellowships. We are also grateful to Randall Hope Johnson for assistance in preparing the manuscript.

\section{Author details \\ ${ }^{1}$ Laboratory of Cell-Cell Interactions, Morphology Department, Institute of Biological Science, Federal University of Minas Gerais, Av. Antônio Carlos, 6627, Pampulha, Belo Horizonte, Minas Gerais 31270-901, Brazil. ²Laboratory of Biomolecules and Vaccines, Agrarian Sciences and Technologic Department, Federal University of Tocantins, Gurupi, Tocantins, Brazil. ${ }^{3}$ Laboratory of Cellular and Molecular Immunology, René Rachou Research Center, Oswaldo Cruz Foundation, Belo Horizonte, MG, Brazil. ${ }^{4}$ Division of Emerging and Transfusion Transmitted Diseases, Office of Blood Research and Review, Center for Biologics Evaluation and Research, US Food and Drug Administration, 10903 New Hampshire Ave, Silver Spring, MD 20993, USA. ${ }^{5}$ Institute of Molecular Medicine, 254 Okhla Industrial Estate, Phase III, New Delhi 110020, India. 'Laboratory of Immunology and Genome of Parasites, Parasitology Department, Institute of Biological Science, Federal University of Minas Gerais, Belo Horizonte, Minas Gerais, Brazil. Laboratory of Diagnosis Biomarkers and Monitoring, René Rachou Research Center, Oswaldo Cruz Foundation, Belo Horizonte, Minas Gerais, Brazil.}

Received: 21 December 2015 Accepted: 21 April 2016 Published online: 30 April 2016

\section{References}

1. Desjeux P. Leishmaniasis: current situation and new perspectives. Comp Immunol Microbiol Infect Dis. 2004;27:305-18.

2. Deane LM, Deane MP. Visceral leishmaniasis in Brazil, geographical distribution and transmission. Rev Inst Med Trop Sao Paulo. 1962;4:198-212.

3. Costa CHN. How effective is dog culling in controlling zoonotic visceral leishmaniasis? A critical evaluation of the science, politics and ethics behind this public health policy. Rev Soc Bras Med Trop. 2011;44:232-42.

4. Coura-Vital W, Marques MJ, Veloso VM, Roatt BM, Aguiar-Soares RDO, Reis LE, Braga, SL, Morais, MH, Reis AB, Carneiro M. Prevalence and factors associated with Leishmania infantum infection of dogs from an urbanarea of Brazil as identified by molecular methods. PLoS Negl Trop Dis. 2011;5(8):e1291.

5. Dye C. The logic of visceral leishmaniasis control. Am J Trop Med Hyg 1996;55:125-30
6. Reis AB, Giunchetti RC, Carrillo E, Martins-Filho OA, Moreno J. Immunity to and the rational search for vaccines against canine leishmaniasis. Trends Parasitol. 2010;26:341-9.

7. Giunchetti RC, Correa-Oliveira R, Martins-Filho O, Teixeira-Carvalho A, Roatt BM, Aguiar-Soares RDO, de Souza JV, das Dores Moreira N, Malaquias LC, Mota e Castro LL, de Lana M, Reis AB. Immunogenicity of a killed Leishmania vaccine with saponin adjuvant in dogs. Vaccine. 2007;25:7674-86.

8. Giunchetti RC, Reis AB, da Silveira-Lemos D, Martins-Filho OA, Corrêa-Oliveira R, Bethony J, Vale AM, da Silva Quetz J, Bueno LL, França-Silva JC, Nascimento E, Mayrink W, Fujiwara R. Antigenicity of a whole parasite vaccine as promising candidate against canine leishmaniasis. Res Vet Sci. 2008;85:106-12.

9. Roatt BM, Aguiar-Soares RD, Vitoriano-Souza J, Coura-Vital W, Braga SL, CorreaOliveira R, Martins-Filho OA, Teixeira-Carvalho A, de Lana M, Fiqueiredo-Gontijo $\mathrm{N}$, Marques MJ, Giunchetti RC, Reis AB. Performance of LBSap vaccine after intradermal challenge with L. infantum and saliva of Lu. longipalpis: immunogenicity and parasitological evaluation. PLoS One. 2012;7(11):e49780

10. Selvapandiyan A, Dey R, Nylen S, Duncan R, Sacks D, Nakhasi HL. Intracellular replication-deficient Leishmania donovani induces long lasting protective immunity against visceral leishmaniasis. J Immunol. 2009;183:1813-20.

11. Fiuza JA, Gannavaram S, Santiago Hda C, Selvapandiyan A, Souza DM, Passos LS, de Mendonça LZ, Lemos-Giunchetti D, Ricci ND, Bartholomeu DC, Giunchetti RC, Bueno LL, Correa-Oliveira R, Nakhasi HL, Fujiwara RT. Vaccination using live attenuated Leishmania donovani centrin deleted parasites induces protection in dogs against Leishmania infantum. Vaccine. 2015;33:280-8.

12. Viana KF, Aguiar-Soares RDO, Ker HG, Resende LA, Souza-Fagundes EM, Dutra WO, Fujiwara RT, da Silveira-Lemos D, Wardini AB, Araújo MS, MartinsFilho OA, Reis AB, Giunchetti RC. Setting the proportion of CD4 + and CD8 + T-cells co-cultured with canine macrophages infected with Leishmania chagasi. Vet Parasitol. 2015;198:62-71.

13. Viana KF, Aguiar-Soares RDO, Roatt BM, Resende LA, Silveira-Lemos D, CorrêaOliveira R, Martins-Filho OA, Moura SL, Zanini MS, Araújo MS, Reis AB, Giunchetti RC. Analysis using canine peripheral blood for establishing in vitro conditions for monocyte differentiation into macrophages for Leishmania chagasi infection and T-cell subset purification. Vet Parasitol. 2013;198:62-71.

14. Fiuza JA, Santiago Hda C, Selvapandiyan A, Gannavaram S, Ricci ND, Bueno LL, Bartholomeu DC, Correa-Oliveira R, Nakhasi HL, Fujiwara RT. Induction of immunogenicity by live attenuated Leishmania donovani centrin deleted parasites in dogs. Vaccine. 2013;31:1785-92.

15. Araújo MS, De Andrade RA, Sathler-Avelar R, Magalhães CP, Carvalho AT, Andrade MC, Campolina SS, Mello MN, Vianna LR, Mayrink W, Reis AB, Malaquias LC, Rocha LM, Martins-Filho OA. Immunological changes in canine peripheral blood leukocytes triggered by immunization with first or second generation vaccines against canine visceral leishmaniasis. Vet Immunol Immunopathol. 2011;141:64-75.

16. Araújo MS, De Andrade RA, Sathler-Avelar R, Teixeira-Carvalho A, Andrade MC, Viana LR, Mayrink W, Reis AB, Malaquias LC, Rocha LM, Martins-Filho OA. T-cell-derived cytokines, nitric oxide production by peripheral blood monocytes and seric anti-Leishmania (Leishmania) chagasi lgG subclass patterns following immunization against canine visceral leishmaniasis using Leishvaccin and Leishmune ${ }^{\circledast}$. Vaccine. 2009;27:1008-17.

17. Costa-Pereira C, Moreira ML, Soares RP, Marteleto BH, Ribeiro VM, França-Dias MH, Cardoso LM, Viana KF, Giunchetti RC, Martins-Filho OA, Araújo MS. Oneyear timeline kinetics of cytokine-mediated cellular immunity in dogs vaccinated against visceral leishmaniasis. BMC Vet Res. 2015;11:92.

18. Fernandes $C B$, Junior $J$, de Jesus $C$, Souza BM, Larangeira DF, Fraga DB, Tavares versa PS, Barrouin-Melo SM . Comparison of two commercial vaccines against visceral leishmaniasis in dogs from endemic areas: IgG, and subclasses, parasitism, and parasite transmission by xenodiagnosis. Vaccine. 2014;32:1287-95.

19. Reis AB, Teixeira-Carvalho A, Giunchetti RC, Roatt BM, Coura-Vital W, Nicolato Rde C, Silveira-Lemos D, Correa-Oliveira R, martins-Filho OA. Cellular immunophenotypic profile in the splenic compartment during canine visceral leishmaniasis. Vet Immunol Immunopathol. 2014;157:190-6.

20. Bourdoiseau C, Hugnet C, Goncalves RB, Vézilier F, Petit-Didider E, Papierok G, Lemesre UL. Effective hummoral and cellular immunoprotective response in LiESApMDP vaccinated protected dogs. Vet Immunol Immunopathol. 2009;128:71-8.

21. Martin V, Vouldouks I, Moreno J, Mc Gahie D, Gueguen S, Cuisinier AM. The protective immune response produced in dogs after primary vaccination with the LiESP/QA-21 vaccine (CaniLeish ${ }^{\circledR}$ ) remains effective against an experimental challenge one year later. Vet Res. 2014;45:69.

22. Pinelli E, Gonzalo RM, Boog CJ, Rutten VP, Gebhard D, del Real G, Ruitenberg EJ. Leishmania infantum-specific T cell lines derived from 
asymptomatic dogs that lyse infected macrophages in a major histocompatibility complex-restricted manner. Eur J Immunol. 1995;25:1594600.

23. Resende LA, Roatt BM, Soares RDA, Viana KF, Mendonça LZ, Lanna MF, Silveira-Lemos D, Correa-Oliveira R, Martins-Filho OA, Fujiwara RT, Carneiro $C M$, Reis $A B$, Giunchetti RC. Cytokine and nitric oxide patterns in dogs immunized with LBSap vaccine, before and after experimental challenge with Leishmania chagasi plus saliva of Lutzomyia longipalpis. Vet Parasitol. 2013;198:371-81.

24. Holzmuller P, Cavaleyra M, Moreaux J, Kovaric R, Vincendeau P, Papierok G, Lemesre JL. Lymphocytes of dogs immunised with purified excretedsecreted antigens of Leishmania infantum co-incubated with Leishmania infected macrophages produce IFN gamma resulting in nitric oxidemediated amastigote apoptosis. Vet Immunol Immunopathol. 2005;106:24757.

25. Lemesre JL, Holzmuller P, Goncalves RB, Bourdoiseau G, Hugnet C, Cavaleyra M, Papierok G. Long-lasting protection against canine visceral leishmaniasis using the LiESAp-MDP vaccine in endemic areas of France: double-blind randomised efficacy field trial. Vaccine. 2007;25:4223-34.

\section{Submit your next manuscript to BioMed Central} and we will help you at every step:

- We accept pre-submission inquiries

- Our selector tool helps you to find the most relevant journal

- We provide round the clock customer support

- Convenient online submission

- Thorough peer review

- Inclusion in PubMed and all major indexing services

- Maximum visibility for your research

Submit your manuscript at www.biomedcentral.com/submit 